\title{
Platelet dynamics in chronic liver disease with special reference to the role of the spleen
}

\author{
P. J. TOGHILL, SHEILA GREEN, AND ROGER FERGUSON
}

From the General Hospital, Nottingham

SUMMARY In all of 12 patients with chronic liver disease, whose platelet dynamics were investigated by the ${ }^{51} \mathrm{Cr}$-labelling technique in association with surface counting, platelet survival was reduced and in 11 the splenic platelet pool was increased. Surface counting showed high initial spleen:liver ratios in eight patients, and in four there was evidence of progressive destruction of platelets in the spleen. In one patient, subsequently shown to have a hepatoma, progressive accumulation of platelets was noted at the tumour site.

The development of techniques of platelet labelling with ${ }^{51} \mathrm{Cr}$ and subsequent external scintillation scanning (Najean et al., 1963; Aster and Jandl, 1964; Harker and Finch, 1969) has allowed a more precise understanding of platelet dynamics in relation to the spleen. In asplenic subjects $90 \%$ of infused autologous labelled platelets may be recovered whereas in health only $60 \%$, indicating that about $30 \%$ of the total body platelet mass is stored in the spleen. The pool of platelets in the spleen is exchangeable and available for the general circulation (Branehög et al., 1973). Platelet recovery decreases with increasing splenomegaly and there is a direct relationship between the size of the splenic platelet pool and the size of the spleen (Kutti et al., 1972).

The spleen in health is a major site of platelet destruction and in various diseases this function may increase considerably. Thus the spleen plays a central role in many of the thrombocytopenic syndromes. At one end of the spectrum, as in idiopathic thrombocytopenic purpura, platelets are destroyed voraciously and prematurely in normalsized spleens, whereas at the other end of the spectrum, in 'big-spleen' disease, platelet survival is often normal but the thrombocytopenia is due to diversion of platelets into large splenic pools.

A low platelet count is a common finding in chronic liver disease and, while there are multiple factors responsible for this, the spleen often plays an important part. Previous studies have reported the results of platelet dynamics in liver disease using the ${ }^{51} \mathrm{Cr}$-labelling techniques (Harker and Finch, 1969;

Received for publication 21 September 1976
Pawelski et al., 1969; Ries and Price, 1974), but imprecise diagnoses have been given and it is difficult to draw accurate conclusions. The present work seeks to define this function of the spleen in a number of patients with chronic liver disease.

\section{Patients and methods}

Twelve patients with chronic liver disease were studied. Clinical details of the patients and the results of liver function tests at the time of the study are shown in the Table. In each case the diagnosis was established by percutaneous or open liver biopsy. Case 11 was studied immediately before and one month after a splenorenal shunt for oesophageal varices. None of the patients had evidence of overt or occult gastrointestinal bleeding or thromboembolic phenomena and all were in a relatively stable clinical state. Studies were also carried out in seven normal people who were undergoing rehabilitation for various disorders and who had no haematological or splenic disease.

All platelet studies were carried out with autologous platelets. Platelets were separated and labelled by a modification of the method of Kutti and Weinfeld (1971). At least $250 \mathrm{ml}$ of whole blood was collected by gravity into plastic bags using a Triple Transfer Pack system (Fenwall Laboratories). The platelet button obtained after sequential centrifugation and separation was resuspended in $10 \mathrm{ml}$ of platelet-poor plasma (PPP) and incubated for 30 minutes with $250 \mu \mathrm{Ci}$ of ${ }^{51} \mathrm{Cr}$ in the form of $\mathrm{Na}_{2} \mathrm{CrO}_{4}$. After incubation the platelets were washed in PPP, to which $50 \mathrm{mg}$ ascorbic acid was added to remove excess chromate, and recentrifuged. The platelet 
Table Clinical and haematological data and results of liver function tests of 12 patients studied

\begin{tabular}{|c|c|c|c|c|c|c|}
\hline $\begin{array}{l}\text { Case } \\
\text { No. }\end{array}$ & $\begin{array}{l}\text { Sex Age } \\
(y r)\end{array}$ & Diagnosis & $\begin{array}{l}H b \\
(g / d l)\end{array}$ & $\begin{array}{l}W B C \\
\left(\times 10^{\circ} / l\right)\end{array}$ & $\begin{array}{l}\text { Platelets } \\
\left(\times 10^{\circ} ! l\right)\end{array}$ & $\begin{array}{l}\text { Mean life span } \\
(h r)\end{array}$ \\
\hline 1 & F 62 & Active chr hepatitis, cirrhosis & $9 \cdot 8$ & $4 \cdot 5$ & 138 & 79 \\
\hline 2 & F 45 & Alcoholic cirrhosis & $12 \cdot 7$ & $8 \cdot 2$ & 239 & 48 \\
\hline 3 & M 37 & Sarcoidosis, cirrhosis & $13 \cdot 3$ & $3 \cdot 5$ & 146 & 22 \\
\hline 4 & F 55 & Alcoholic cirrhosis & $10 \cdot 5$ & $4 \cdot 9$ & 110 & 129 \\
\hline 5 & M 55 & Alcoholic cirrhosis & $13 \cdot 1$ & $7 \cdot 1$ & 72 & 75 \\
\hline 6 & F 77 & Alcoholic cirrhosis & $14 \cdot 0$ & $7 \cdot 9$ & 126 & 75 \\
\hline 7 & M 49 & Alcoholic cirrhosis & $12 \cdot 6$ & $8 \cdot 6$ & 223 & 98 \\
\hline 8 & F 76 & Cryptogenic cirrhosis & $9 \cdot 9$ & $4 \cdot 8$ & 144 & 120 \\
\hline 9 & M 61 & Alcoholic cirrhosis and hepatoma & $10 \cdot 8$ & $14 \cdot 3$ & 139 & 69 \\
\hline 10 & F 60 & Active chr hepatitis, cirrhosis & $12 \cdot 5$ & $3 \cdot 5$ & 65 & 79 \\
\hline \multicolumn{7}{|c|}{ 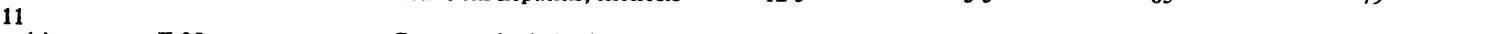 } \\
\hline (a) & F 35 & Cryptogenic cirrhosis & $8 \cdot 5$ & $7 \cdot 3$ & 33 & 43 \\
\hline (b) & F 35 & After splenorenal shunt & $11 \cdot 4$ & 8.6 & 60 & 82 \\
\hline 12 & M 60 & Alcoholic cirrhosis & 11.6 & $11 \cdot 6$ & 77 & 52 \\
\hline
\end{tabular}

* Spleen weight at necropsy.

$\mathbf{N}=$ Normal surface counting pattern.

EIS = Excess initial splenic uptake pattern.

PS = Progressive splenic pattern.

PL = Progressive liver pattern.

button was resuspended in $25 \mathrm{ml}$ PPP, a small aliquot taken, and a known volume of the remainder, usually $20-25 \mathrm{ml}$, injected into the patient by disposable plastic syringe. As equilibration of platelets in the splenic pool is known to take up to 45 minutes no samples were taken in the first hour after injection. A series of three blood samples were taken between one and three hours after the injection. Thereafter, samples were taken daily.

Platelet-bound radioactivity was estimated in $10 \mathrm{ml}$ of blood in plastic disposable tubes. Each sample was centrifuged at $220 \mathrm{~g}$ for 10 minutes and the supernatant platelet-rich plasma (PRP) counted for radioactivity and platelet concentration. From these figures and from synchronous peripheral whole blood platelet concentrations an estimate of the platelet-bound radioactivity in whole blood could be obtained. All platelet counts were made with a Coulter counter (Model FN).

The platelet survival curves were derived from the serial estimates of platelet-bound radioactivity in peripheral blood. The highest activity of any sample taken between 60 and 180 minutes after injection was taken as the $100 \%$ sample, this being considered zero time. Survivals were expressed as the number of hours taken for the platelet-bound radioactivity to fall to $50 \%$ of its zero level $\left(\mathrm{T}_{50}{ }^{51} \mathrm{Cr}\right.$ ) and also as the mean life span (MLS). The MLS of the platelets was estimated from the survival curves using the methods suggested by Harker and Finch (1969).

Platelet recovery was calculated as the proportion of infused platelet-bound radioactivity recoverable in the peripheral blood at zero time. The total infused radioactivity was corrected for non-platelet bound radioactivity. Total blood volume (TBV) was estimated by the method of Nadler et al. (1962). Platelet recovery was derived from the ratio

Platelet-bound activity per $\mathrm{ml}$ of blood $\times \mathrm{TBV} \times 100$ Injected platelet-bound activity

Surface radioactivity was measured with a scintillation counter with a collimator of $3 \mathrm{~cm}$ diameter and $5 \mathrm{~cm}$ depth. Radioactivity was recorded from the following sites with the patient supine and the counter vertical (a) heart, over the left sternal edge from third to fifth spaces; $(b)$ liver, in the right midclavicular line $4 \mathrm{~cm}$ above the costal margin; (c) spleen, between the left mid-clavicular and axillary line over the seventh interspace. When the liver or spleen was enlarged surface counting was carried out over the geometrical centre of the anterior projection of the organ.

Recordings were expressed as organ:heart and spleen:liver ratios. The initial surface counting measurements were delayed at least 45 minutes after the injection of labelled cells to enable complete splenic mixing to occur. This initial count gave an indication of the degree of early sequestration or pooling. Subsequent surface counting over the next few days gave an indication of platelet destruction in the spleen. When the results of surface counting were expressed as spleen:liver ratios, as in the report of Cooper et al. (1972), an initial spleen:liver ratio of greater than 2.5 was considered to show dominant early splenic sequestration or pooling. A rising spleen:liver ratio on late surface counting indicated preferential splenic destruction of platelets.

Spleen size was assessed by $99 \mathrm{mTc}$ scintiscanning. The spleen volume was calculated according to the formula $v=0.3 \sqrt{ } a^{3}$, where $v$ represented the 
Table continued

\begin{tabular}{|c|c|c|c|c|c|c|c|}
\hline $\begin{array}{l}\text { Platelet } \\
\text { recovery } \\
(\%)\end{array}$ & $\begin{array}{l}\text { Initial } \\
\text { spleen:liver } \\
\text { ratio }\end{array}$ & $\begin{array}{l}\text { Organ } \\
\text { uptake } \\
\text { pattern }\end{array}$ & $\begin{array}{l}\text { Estimated } \\
\text { spleen volume } \\
(\mathrm{ml})\end{array}$ & $\begin{array}{l}\text { Bilirubin } \\
(\mu \mathrm{mol} / \mathrm{l})\end{array}$ & $\begin{array}{l}\text { Alkaline } \\
\text { phosphatase } \\
(I U / l)\end{array}$ & $\begin{array}{l}\text { Aspartute } \\
\text { aminotransferase } \\
(I U \mid l)\end{array}$ & $\begin{array}{l}\text { Serum proteins } \\
\text { albumin/globulin } \\
(\mathrm{g} / \mathrm{l})\end{array}$ \\
\hline 27 & $7 \cdot 8$ & EIS & 607 & 28 & 468 & 43 & $32 / 31$ \\
\hline - & 0.9 & PS & 300 & 47 & 282 & 35 & $29 / 30$ \\
\hline 20 & 1.8 & PS & 609 & 26 & 224 & 28 & $45 / 28$ \\
\hline 60 & $1 \cdot 3$ & $\mathbf{N}$ & 394 & 26 & 192 & 34 & $40 / 33$ \\
\hline 23 & $6 \cdot 2$ & EIS and PS & 231 & 41 & 424 & 100 & $18 / 68$ \\
\hline 46 & $1 \cdot 1$ & $\mathbf{N}$ & 282 & 93 & 340 & 55 & $23 / 38$ \\
\hline 40 & $4 \cdot 5$ & EIS & 404 & 188 & 424 & 63 & $28 / 41$ \\
\hline 31 & $9 \cdot 2$ & EIS & 248 & 18 & 1360 & 21 & $23 / 52$ \\
\hline 22 & $4 \cdot 2$ & EIS and PL & $380^{*}$ & 85 & 232 & 16 & $13 / 66$ \\
\hline 25 & $2 \cdot 8$ & EIS & 535 & 10 & 116 & 19 & $39 / 14$ \\
\hline 10 & \multicolumn{3}{|c|}{ No surface counting studies } & 43 & 440 & 83 & $37 / 42$ \\
\hline 18 & $7 \cdot 8$ & EIS and PS & 647 & 62 & 484 & 102 & $35 / 36$ \\
\hline 38 & $2 \cdot 5$ & EIS & 350 & 46 & 498 & 35 & $31 / 31$ \\
\hline
\end{tabular}

Conversion: SI to traditional units-Bilirubin: $1 \mu \mathrm{mol} / 1 \approx 0.06 \mathrm{mg} / 100 \mathrm{ml}$.

volume of the spleen in $\mathrm{ml}$ and $a$ the largest surface area in $\mathrm{cm}^{2}$ (Fischer, 1970).

\section{Results}

The clinical, haematological, and isotopic studies are summarised in the Table.

\section{PLATELET SURVIVALS}

Platelet survival was linear in seven normal subjects with a MLS of 172-230 hours. This was comparable with other series in which similar techniques were used (Aster and Keene, 1969; Kutti and Weinfeld, 1971; Ries and Price, 1974). In the patients with chronic liver disease platelet survival was reduced with a MLS ranging from 22-129 hours. None of the patients had normal platelet survival. No statistical relationship was obtained between platelet survival and spleen size, peripheral platelet count, and platelet recovery, but in cases 2 and 3 with the shortest survival times there was progressive accumulation of activity in the spleen, indicating preferential destruction of platelets in the spleen.

\section{PLATELET RECOVERY}

In seven normal patients platelet recovery was from 56-70\%, indicating splenic platelet pools of about one-third of the total platelet mass. With the exception of one patient (case 4), platelet recovery was low in all patients with chronic liver disease with a range from 46 to $10 \%$, indicating large splenic platelet pools. There was no relationship between spleen size and platelet recovery. In case 11 the platelet recovery rose from $10 \%$ to $18 \%$ after the splenorenal shunting. The spleen was not scanned

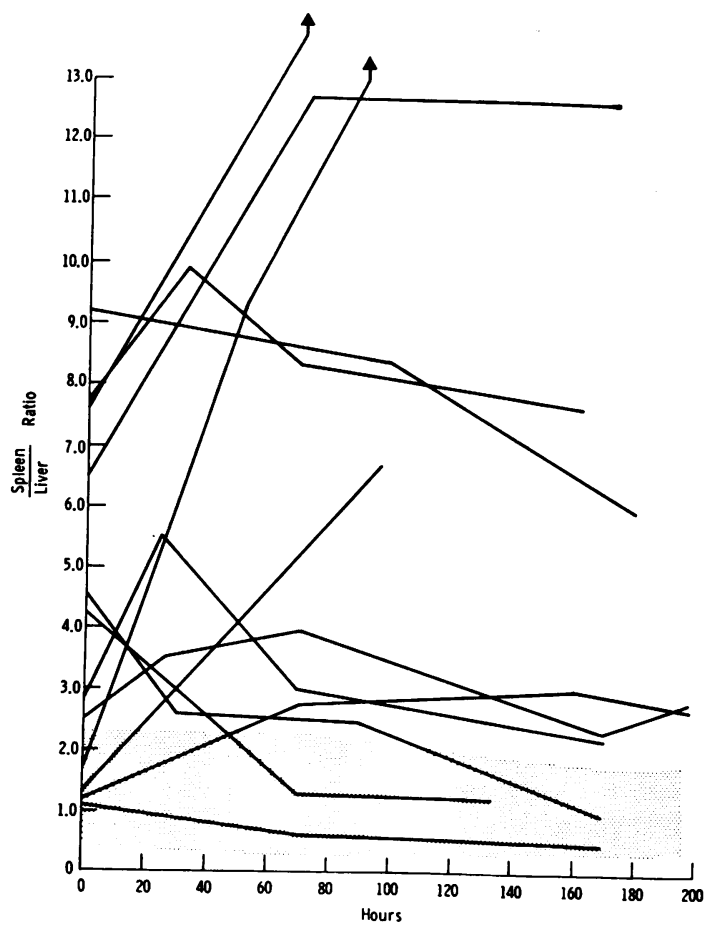

Figure Surface counting studies showing spleen:liver ratios. Hatched area represents the range in normal subjects studied.

preoperatively but its reduction in size after the splenorenal shunt was $9 \mathrm{~cm}$ in its longest diameter.

SURFACE COUNTING PATTERNS

The spleen:liver ratios in the patients studied are 
shown in the Figure. When surface counting was carried out for the first time one hour after injection of autologous labelled platelets in normal subjects the spleen:liver ratio was from $0 \cdot 7-2 \cdot 3$. In the patients with liver disease the range for spleen:liver ratio was $0.9-9.2$ (mean $4.2 \pm 2.9$ ). In 8 of the 12 patients with liver disease the initial spleen:liver ratio exceeded 2.5 and indicated excess initial sequestration (EIS) of platelets in the spleen, presumably owing to pooling.

With subsequent surface counting 4 patients (cases 2, 3, 5, and 11b) showed continued accumulation of activity over the spleen with rising spleen: liver ratios, presumably owing to progressive splenic destruction of platelets (PS). In one patient (case 9) there was excess initial splenic sequestration, but a later steady increase in activity over the liver gave a falling spleen:liver ratio. This patient was found at necropsy to have a hepatoma and possibly there was consumption of platelets in the vascular tumour, which was in fact just under the counting site.

\section{Discussion}

The low platelet counts often found in chronic liver disease are known to result from the interaction of many complex factors. Undoubtedly thrombopoiesis in liver disease may be impaired by the toxic effects of alcohol or by folate deficiency. At times thrombocytopenia may be aggravated by consumption of platelets due to gastrointestinal bleeding. However, there is no doubt that in 'steady state' syndromes the spleen plays a central role in the distribution and destruction of platelets.

The moderate reduction of the platelet life span shown in most of our patients compares with the findings of Cohen et al. (1961) in six patients with portal hypertension of unknown aetiology. Harker and Finch (1969), however, found normal platelet survival in four patients with 'congestive splenomegaly' as did Pawelski et al. (1969) in one patient with portal hypertension. Castaldi and Firkin (1963) reported very short platelet survival times in their patients with portal hypertension, but since all of them had been previously transfused they thought that the brief survival of homologous platelets might have been due to isoimmunisation. Interestingly, in our two patients (cases 2 and 3) with short platelet survivals progressive splenic destruction of platelets occurred.

Increased platelet pooling in the spleen was found in all our patients except in case 4 . Harker and Finch (1969) also reported large splenic platelet pools with low recoveries of from 7 to $23 \%$ in their patients with congestive splenomegaly. In patients with gross splenomegaly due to haematological $\stackrel{\stackrel{0}{\vec{\sigma}}}{-}$ diseases the platelet pool size is directly proportional to spleen size (Kutti et al., 1972). However, in ouro⿱ patients with chronic liver disease spleen sizes were 0 rarely more than thrice normal size and no such음 direct relationship occurred. Considering spleen $\frac{\bar{\rho}}{\vec{b}}$ size alone, the platelet pools in chronic liver disease $\stackrel{\mathbb{\Phi}}{\propto}$ would seem to be larger than expected. This may be related to portal hypertension. We did not measure $\rightarrow$

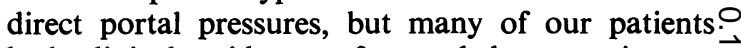
had clinical evidence of portal hypertension as $\vec{\omega}$ evidenced by oesophageal and gastric varices.

Sequential surface counting over the spleen to assess degrees of platelet destruction is of doubtful w value (Aster, 1972). Much depends on the techniques of scanning, both in collimation and organ geometry $\omega$ (Bowring and Glass, 1974). With normal or mildly $\checkmark$ enlarged spleens posterior scanning may well be우 more accurate and may reveal degrees of splenic sequestration unsuspected on anterior scanning $?$ (Ries and Price, 1974). While these surface counting techniques may predict accurately the response to $\vec{\theta}$ splenectomy in the idiopathic thrombocytopenic $\checkmark y$ syndromes (Najean and Ardaillou, 1971) they are less reliable in the 'big spleen' syndromes. In onlyo four of our 12 patients were there progressive increases in splenic activity implying excessive splenic destruction of platelets. In these patients the $\frac{\mathrm{O}}{\mathrm{D}}$

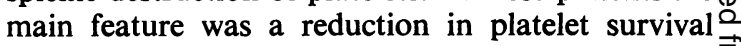
which was not necessarily related to any consistent $\overrightarrow{0}$ reduction in the peripheral platelet count.

Although in health splenectomy does not extend the platelet life span (Harker, 1971) platelet survival $\stackrel{\circ}{-}$ in portal hypertension is improved after splenectomy (Pawelski et al., 1969). How much this effect is responsible for the encouraging rise in platelet count 3 . after splenectomy in active chronic hepatitis (Boye $\stackrel{\circ}{\circ}$ et al., 1972) is uncertain. Undoubtedly in some patients with active chronic hepatitis the thrombo-o cytopenia may be part of an 'immune crisis' (Toghill and Green, 1975), and although the role of splenec-o tomy in these circumstances is speculative some results have been heartening (Fodor and Barbarino, $O$ 1972). Reducing portal pressure may be important $N$ in improving platelet survival, as was the case with $\mathrm{CU}^{2}$ our patient (Case 11) after a splenorenal shunt and 0 in other patients with portocaval shunting (Castaldi and Firkin, 1963).

From these results no clear pattern emerges of the role of the spleen in the thrombocytopenia of liver 0 disease. Most patients with chronic liver disease $\vec{D}$ have splenic platelet pools larger than would be $\stackrel{\mathbb{Q}}{\Omega}$ expected from spleen size alone and all have a $\frac{\vec{\phi}}{\circ}$ reduced platelet survival. However, neither of these $\frac{\varrho}{\sigma}$ factors relates directly to the peripheral platelet< count, which may in some patients be well maintained. 
We gratefully acknowledge financial support from the Trent Regional Health Authority and the Dunhill Research Trust.

\section{References}

Aster, R. H. (1972). Platelet sequestration studies in man. British Journal of Haematology, 22, 259-263.

Aster, R. H. and Jandl, J. H. (1964). Platelet sequestration in man. 1. Methods. Journal of Clinical Investigation, 43, 843-855.

Aster, R. H. and Keene, W. R. (1969). Sites of platelet destruction in idiopathic thrombocytopenic purpura. British Journal of Haematology, 16, 61-73.

Bowring, C. S. and Glass, H. I. (1974). Collimation and surface counting in haematology. Journal of Clinical Pathology, 27, 751-756.

Boye, N. P., Nordöy, A., and Gjone, E. (1972). Splenectomy in active chronic hepatitis. Scandinavian Journal of Gastroenterology, 7, 747-750.

Branehög, I., Weinfeld, A., and Roos, B. (1973). The exchangeable splenic platelet pool studied with epinephrine infusion in idiopathic thrombocytopenic purpura and in patients with splenomegaly. British Journal of Haematology, 25, 239-248.

Castaldi, P. A. and Firkin, B. G. (1963). Studies of the life span and fate of platelets. Australasian Annals of Medicine, 12, 333-341.

Cohen, P., Gardner, F. H., and Barnett, G. O. (1961). Reclassification of the thrombocytopenias by the $\mathrm{Cr}^{51}$ labelling method for measuring platelet life span. New England Journal of Medicine, 264, 1294-1299.

Cooper, M. R., Hansen, K. S., Maynard, C. D., Elrod, I. W., and Spurr, C. L. (1972). Platelet survival and sequestration patterns in thrombocytopenic disorders. Radiology, 102, 89-100.

Fischer, J. (1970). Die Milzszintigraphie als Method zur funkionellen Milzanlyse. In The Spleen, edited by Karl
Lennert and Dieter Harms, pp. 336-346. SpringerVerlag, Berlin.

Fodor, O. and Barbarino, F. (1972). Splenectomy in chronic hepatitis (Rumanian). Medicina Interna (Buc.), 24, 259-266.

Harker, L. A. (1971). The role of the spleen in thrombokinetics. Journal of Laboratory and Clinical Medicine, 77, 247-253.

Harker, L. A. and Finch, C. A. (1969). Thrombokinetics in man. Journal of Clinical Investigation, 48, 963-974.

Kutti, J. and Weinfeld, A. (1971). Platelet survival in man. Scandinavian Journal of Haematology, 8, 336-346.

Kutti, J., Weinfeld, A., and Westin, J. (1972). The relationship between splenic platelet pool and spleen size. Scandinavian Journal of Haematology, 9, 351-354.

Nadler, S. B., Hidalgo, J. U., and Bloch, T. (1962). Prediction of blood volume in normal human adults. Surgery, 51, 224-232.

Najean, Y. and Ardaillou, N. (1971). The sequestration site of platelets in idiopathic thrombocytopenic purpura: its correlation with the results of splenectomy. British Journal of Haematology, 21, 153-164.

Najean, Y., Ardaillou, N., Cean, J., Larrieu, M., and Bernard, J. (1963). Survival of radiochromium labelled platelets in thrombocytopenias. Blood, 22, 718-732.

Pawelski, S., Rudowski, W., Rechowicz, K., Zdziechowska, H., Konopka, L., Kotelba-Witkowska, B., Klawe, Z., and Nowak, S. (1969). The effect of splenectomy on the clinical picture and survival time of platelets in thrombocytopenia. Haematologia, 3, 289-297.

Ries, C. A. and Price, D. C. (1974). $\left[{ }^{51} \mathrm{Cr}\right]$ platelet kinetics in thrombocytopenia. Annals of Internal Medicine, 80, 702-707.

Toghill, P. J. and Green, S. (1975). Haematological changes in active chronic hepatitis with reference to the role of the spleen. Journal of Clinical Pathology, 28, 8-11. 